Article

\title{
Effect of Arbuscular Mycorrhizal Fungi (AMF) and Plant Growth-Promoting Bacteria (PGPR) Inoculations on Elaeagnus aangustifolia L. in Saline Soil
}

\author{
Jing Pan ${ }^{1,2}{ }^{(}$, Cuihua Huang ${ }^{1}\left(\mathbb{D}\right.$, Fei Peng ${ }^{1,3}{ }^{(}$, , Wenjuan Zhang ${ }^{1,2}$, Jun Luo ${ }^{4}$, Shaoxiu Ma ${ }^{1}$ and \\ Xian Xue ${ }^{1, *(\mathbb{D}}$ \\ 1 Drylands Salinization Research Station, Key Laboratory of Desert and Desertification, Northwest Institute of \\ Eco-Environment and Resources, Chinese Academy of Sciences, Lanzhou 730000, China; \\ panjing@lzb.ac.cn (J.P.); hch@lzb.ac.cn (C.H.); pengfei@lzb.ac.cn (F.P.); zhangwenjuan@lzb.ac.cn (W.Z.); \\ shaoxiuma@gmail.com (S.M.) \\ 2 University of Chinese Academy of Sciences, Beijing 100049, China \\ 3 International platform for dryland research and education, arid land research center, Tottori University, \\ Tottori 680-8550, Japan \\ 4 School of land and resources, China west normal university, Nanchong 637002, China; luojunxmx@126.com \\ * Correspondence: xianxue@1zb.ac.cn; Tel.: +86-931-4967567
}

Received: 30 December 2019; Accepted: 28 January 2020; Published: 1 February 2020

\begin{abstract}
Arbuscular mycorrhizal fungi (AMF) and plant growth-promoting rhizobacteria (PGPR) are considered highly-efficient agents for conferring salt tolerance in host plants and improving soil fertility in rhizosphere. However, information about the inoculation of beneficial microbes on halophytes in arid and semi-arid regions remains inadequate. The objective of this study was to evaluate the influence of AMF (Glomus mosseae) inoculation, alone or in combination with PGPR (Bacillus amyloliquefaciens), on biomass accumulation, morphological characteristics, photosynthetic capacity, and rhizospheric soil enzyme activities of Elaeagnus angustifolia L., a typical halophyte in the northwest of China. The results indicate that, for one-year-old seedlings of Elaeagnus angustifolia L., AMF significantly promoted biomass accumulation in aboveground organs, increased the numbers of leaves and branches, and improved the leaf areas, stem diameters and plant height. AMF-mediated morphological characteristics of aboveground organs favored light interception and absorption and maximized the capacities for photosynthesis, transpiration, carbon dioxide assimilation and gas exchange of Elaeagnus angustifolia L. seedlings in saline soil. AMF also promoted root growth, modified root architecture, and enhanced soil enzyme activities. Elaeagnus angustifolia L. was more responsive to specific inoculation by AMF than by a combination of AMF and PGPR or by solely PGPR in saline soils. Therefore, we suggest that G. mosseae can be used in saline soil to enhance Elaeagnus angustifolia L. seedlings growth and improve soil nutrient uptake. This represents a biological technique to aid in restoration of saline-degraded areas.
\end{abstract}

Keywords: halophyte; arbuscular mycorrhizal fungi; plant growth promoting rhizobacteria; morphological characteristics; photosynthesis; soil enzymes

\section{Introduction}

Soil salinity is a severe agronomical, ecological, and socioeconomic concern in most arid and semi-arid regions of the world [1,2]. Most of salt-affected land has become saline owing to natural accumulation of salts over long periods of time, while others are caused by anthropogenic 
mismanagement [1]. Salinity in soil provokes the loss of natural plant communities [2], destroys ecosystem diversity [3], reduces the production of crops and forages [4], accelerates the process of soil degradation [2], and reduces the potential utilization of halophytes as crops [5]. Salinity not only adversely affects agriculture and ecosystems, but also poses a threat to public health and security [6], which further exacerbates unsustainable livelihoods and inequalities in socio-economic development [7]. Moreover, saline soil is sensitive to global climate change, this further intensifies salinization [8,9]. It is estimated that salinization will threaten more than $50 \%$ of arable land worldwide by 2050 [10]. Hence, this silent hazard will continue to threaten agricultural sustainability, food security, ecosystem stability, human health and income generation.

The northwest arid area of China is one such region that is highly vulnerable to global climate change, and is widely affected by soil salinization [11]. The Minqin Oasis is considered an essential part of the Chinese Silk Road in the northwest arid area of China. As one of the world's driest and most fragile regions, the Minqin oasis has witnessed significant impacts of both natural and anthropogenic factors on soil salinization. Harsh natural conditions, such as very high temperatures, low rainfall, and strong evaporation, lead to soil natural salinization [11,12]. Many organism inhabitants are well well adapted to this naturally saline environment. Anthropogenic factors, such as outdated irrigation systems combined with excessive groundwater extraction, execrate soil secondary salinization. Secondary salinization inhibits plant growth, reduces crop yield, changes the habitat pattern of halophytes, and causes vegetation degeneration and ecosystem deterioration in the Minqin Oasis [13-15], which further results in wasted land. If this wasted land is not improved in a timely manner, Minqin oasis will become a new source of salt dust and a national ecological crisis zone in China. Therefore, strengthening saline soil research in the Minqin Oasis not only has a positive effect on the regional biodiversity conservation, but also guides the study of ecosystems in the northwest arid areas of China.

Elaeagnus angustifolia L., a very important halophytic perennial tree in the Minqin Oasis, has excellent tolerance to salinization, sand and barren land [16], and has high value in ecology, economics and medicine $[17,18]$. However, the persistent expansion and aggravation of soil salinization in the Minqin Oasis, driven by both natural and anthropogenic factors, is threatening the habitats of Elaeagnus angustifolia L. Salinity intrusion in this area not only adversely affects the growth, productivity and distribution of Elaeagnus angustifolia L. but also lowers the sheltering effects of the protective forest dominated by Elaeagnus angustifolia L. to farmland [16]. Previous studies have reported that indigenous halophytes can survive in saline habitats thanks to the co-evolution of halophytes and microbes $[2,19,20]$. The collaboration of halophytes and microbes not only enhances plant biomass and population diversity [21,22] but also improves soil microbial activities and other soil properties [19,23]. Therefore, there is potential to exploit beneficial soil microbes to promote the growth of Elaeagnus angustifolia L. and to further use these microbes to ameliorate saline soil in the Minqin Oasis.

Arbuscular mycorrhizal fungi (AMF) and plant growth-promoting rhizobacteria (PGPR) are beneficial below-ground microbes that directly associate with plant roots [24,25]. Previous studies showed that the growth-promoting effects on host glycophytes under salt stress are attributable to AMF and PGPR, which could enhance salt tolerance by altering root morphology, modifying root-to-shoot communication, increasing nutrients uptake, maintaining ion homeostasis, decreasing oxidative damage, and elevating photosynthetic capacity $[10,24,26,27]$. As bio-inoculants, AMF and PGPR also play vital roles in soil biological activity, benefiting the remediation of saline soil, and consequently increasing the suitability of saline soil to plant growth $[28,29]$. However, little is known about the inoculation effects of different beneficial microorganisms on the biomass accumulation, morphological characteristics, photosynthetic capacities, and rhizospheric soil enzymes of halophytes, especially Elaeagnus angustifolia L. in saline soil.

Based on this existing knowledge, the objective of our study is to test the effects of AMF inoculation, both alone and in combination with PGPR, on Elaeagnus angustifolia L. in saline soil. We address the following research questions: (1) what are the impacts of AMF and PGPR inoculations on biomass accumulation, morphological characteristics, photosynthesis and soil enzymes of Elaeagnus angustifolia 
L. in saline soils? (2) Is species diversity or a particular key species most important in controlling the growth characteristics and salt tolerance of Elaeagnus angustifolia L.?

\section{Materials and Methods}

\subsection{Study Site}

The study area is located at the Drylands Salinization Station affiliated to the Northwest Institute of Eco-Environment and Resources, Chinese Academy of Sciences, China, which is located in the low

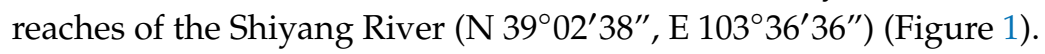

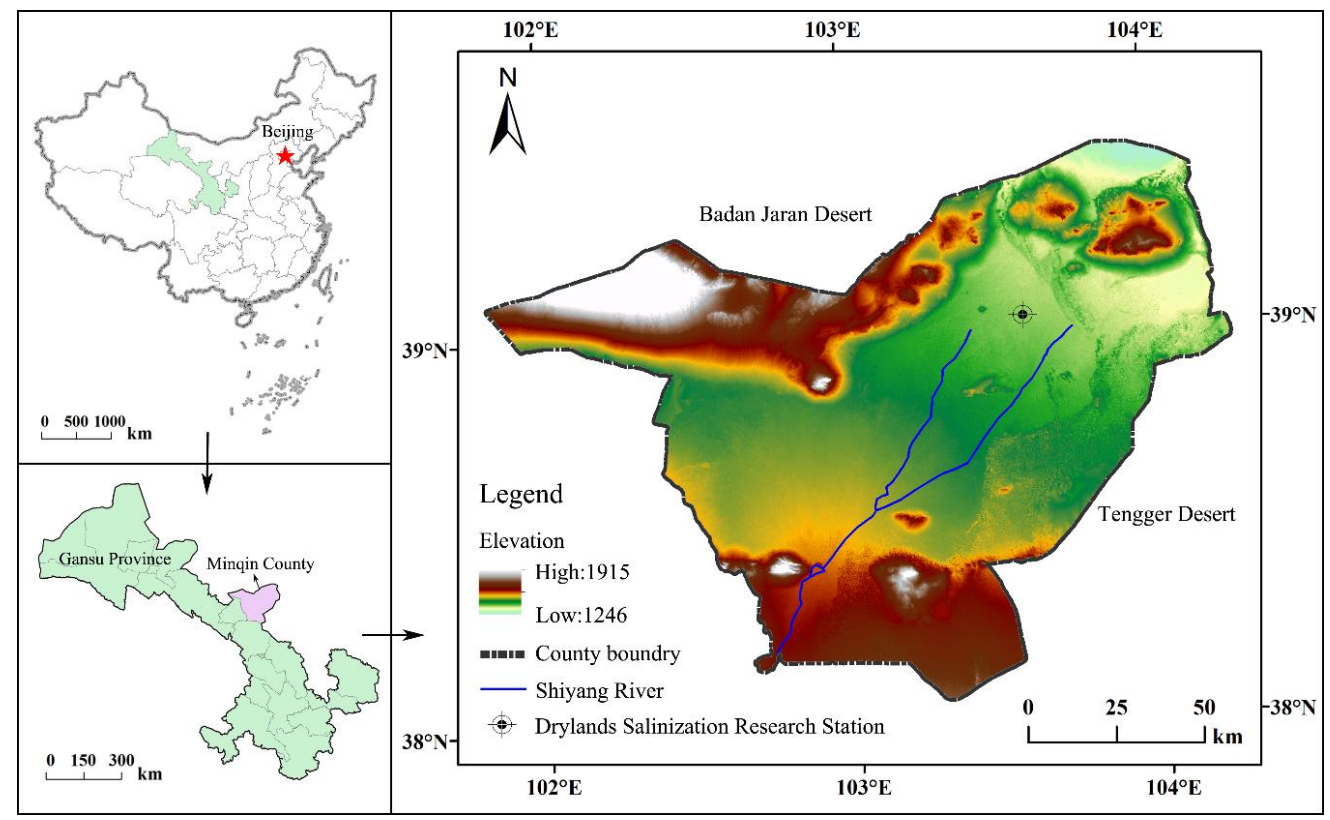

Figure 1. The location of the Drylands Salinization Station.

Over a 30-year period, the mean annual precipitation is $119.46 \mathrm{~mm}$. The maximum annual precipitation is $202 \mathrm{~mm}$ in 1994, and the minimum annual precipitation is $77.3 \mathrm{~mm}$ in 1989 (Figure 2a). In 2007, the total precipitation is $95 \mathrm{~mm}$. The maximum temperature is $42.13^{\circ} \mathrm{C}$ in July, and minimum temperature is $-25.9^{\circ} \mathrm{C}$ in January. The maximum and minimum photosynthetic active radiation is $730.2 \mu \mathrm{mol} \mathrm{m}^{-2} \mathrm{~s}^{-1}$ and $41.57 \mu \mathrm{mol} \mathrm{m}^{-2} \mathrm{~s}^{-1}$, respectively (Figure $2 \mathrm{~b}$ ).

\subsection{Soil and Plant Treatment}

Soil and seeds utilized in this experiment were collected from the Drylands Salinization Station affiliated to the Northwest Institute of Eco-Environment and Resources, Chinese Academy of Sciences, China, which is located in the low reaches of the Shiyang River (N 39 $02^{\prime} 38^{\prime \prime}$, E $\left.103^{\circ} 36^{\prime} 36^{\prime \prime}\right)$ (Figure 1). The soil was collected from the top layer $(0-20 \mathrm{~cm})$ of an agricultural field, then passed through a $5 \mathrm{~mm}$ sieve. The soil was classified into Orthic Halosols in the Chinese taxonomic system and was identified as Ustifluvent in the taxonomic system of United States Department of Agriculture [30,31]. The soil used throughout this experiment before planting had the following properties: $\mathrm{pH}$ of $8.14 \pm 0.02$, EC of $2015 \pm 15 \mu \mathrm{S} \mathrm{cm}^{-1}$ (water-soil ratio of 5:1), organic carbon content of $9.36 \pm 0.18 \mathrm{~g} \mathrm{~kg}^{-1}$, total $\mathrm{N}$ of $0.61 \pm 0.01 \mathrm{~g} \mathrm{~kg}^{-1}$, available P of $16.41 \pm 0.81 \mathrm{~kg} \mathrm{ha}^{-1}$, and available $\mathrm{K}$ of $47.75 \mathrm{mg} \mathrm{kg}^{-1}$ [11]. Healthy fruits of Elaeagnus angustifolia L. were selected carefully, and peeled to obtain the seeds. These seeds were surface-sterilized with $\mathrm{NaOCl}(5 \%)$ for $10 \mathrm{~min}$ and then thoroughly rinsed with deionized water to completely remove all traces of $\mathrm{NaOCl}$. 


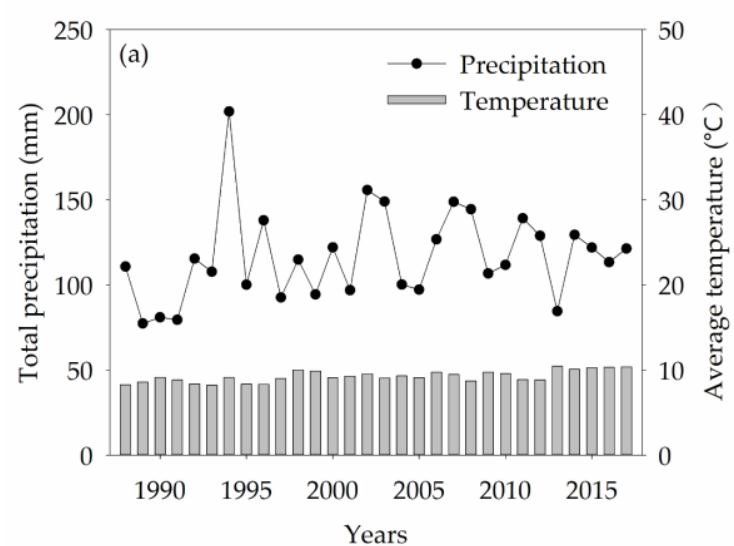

(a)

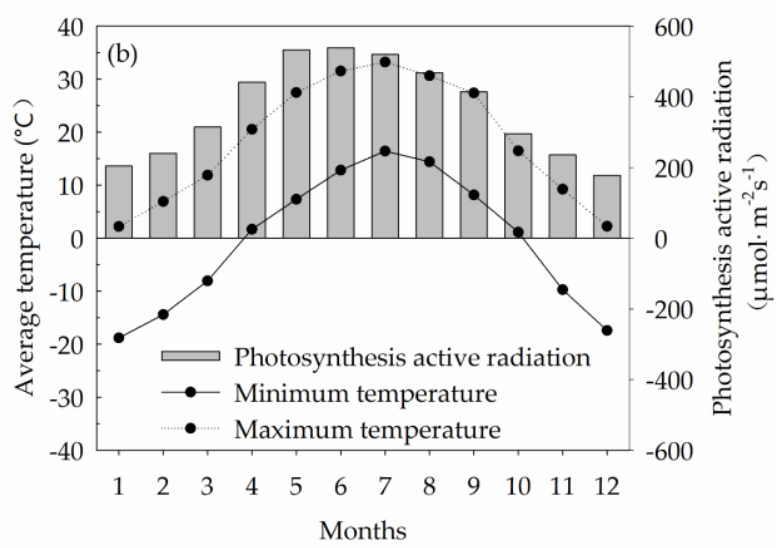

(b)

Figure 2. The characteristics of precipitation, temperature and photosynthesis active radiation (from meteorological data in the Drylands Salinization Station). (a) total precipitation amount and average temperature per year, $(\mathbf{b})$ average temperature and photosynthesis active radiation per month.

\subsection{Microbial Inoculum}

Glomus mosseae, the most efficient fungus to help plants to cope with the detrimental effects of salt stress [32]. The strain of G. mosseae was commercially provided by the Institute of Plant Nutrition and Resources, Beijing Academy of Agriculture and Forestry Sciences, which was isolated from the rhizospheric soil of Populus euphratica in Xinjiang Autonomous Region, China. G. mosseae was multiplied using Sorghum bicolor as host plant and a mixture of soil, river sand, perlite and quartz sand as substrate (with a mixing ratio of 2:3:3:3) for 4 months. The AMF inoculum contained growth substrate, spores (density of approximately 75 per $10 \mathrm{~g}$ dry substrate), mycelium and infected root fragments of G. mosseae. Each pot was inoculated with $100 \mathrm{~g}$ inoculum for mycorrhizal treatment. Non-mycorrhizal treatment received $100 \mathrm{~g}$ sterilized AM inoculum $\left(160^{\circ} \mathrm{C}, 4 \mathrm{~h}\right)$. Bacillus amyloliquefaciens FZB42 was grown overnight on Luria-Bertani liquid medium with constant shaking at $200 \mathrm{rpm}$ [33]. After incubating overnight, cells were obtained by centrifugation at 10,000 rpm for $6 \mathrm{~min}$, washed once, and re-suspended in deionized water to $1.0 \times 10^{8}$ colony-forming units $/ \mathrm{mL}$ for use as the PGPR inoculum $[33,34]$.

\subsection{Plant Growth Conditions and Experimental Design}

A pot experiment was performed outdoors under natural conditions in the Drylands Salinization Station during 11 May to 29 August 2017. Five seeds were sown in experimental pots filled with $1.3 \mathrm{~kg}$ saline soil. The pot bottom was covered by mesh $(38 \mu \mathrm{m})$ to avoid root growth out of the pot. The experiment consisted of four treatments as follows: (1) Control: seeds were soaked in $40 \mathrm{ml}$ sterile water for $30 \mathrm{~min}$ and the soil was mixed with sterile AMF inoculum. (2) AM treatment: seeds were soaked in $40 \mathrm{ml}$ sterile water for $30 \mathrm{~min}$ and soil was mixed with AMF inoculum. (3) PGPR treatment: seeds were inoculated with PGPR inoculum for $30 \mathrm{~min}$, soil was mixed with sterile AMF inoculum. (4) Co-microbial treatment: soil was treated following the AMF treatment; seeds were treated following the PGPR treatment. After 15 days of emergence, thinning was performed and one seedling was left in each pot. Seedlings had roughly equal heights. Then, seedlings in the PGPR treatment and co-microbial treatment were irrigated with $40 \mathrm{~mL}$ PGPR inoculum $\left(10^{8} \mathrm{CFU} / \mathrm{ml}\right)$. All plants were regularly irrigated with water from Shiyang River to maintain soil moisture near field capacity. Each treatment contained eight pots and the seedlings were harvested 110 days after sowing. Five pots were used to measure the parameters of plant biomass, organ morphology, and photosynthesis, and the remaining three pots were used to determine soil enzymes. 


\subsection{Parameter Measurements}

\subsubsection{Plant Biomass, Organ Morphology, and AMF Colonization Rate}

Five replicates of plant height and leaf number were measured and recorded before the end of the experiment. The basal stem diameter was determined by a Vernier caliper. Total leaf area was scanned by an Epson Expression 1480 digital scanner (Epson (China) Co., Beijing, China) and measured by the measurement tool in Adobe Photoshop CS4 software (Version 11.0.1). Plant fresh mass was measured at final harvest, plant dry mass was determined and calculated after oven drying at $60^{\circ} \mathrm{C}$ to constant mass [35]. The degree of succulence was expressed as the ratio of fresh mass to dry mass [36,37]. Specific stem length was calculated as the ratio of plant height to stem dry mass [38]. AMF colonization rate was also measured at final harvest using fresh root segments which was cut into $1 \mathrm{~cm}$ length [39].

The fresh roots were carefully washed under running tap water, dried with paper towels and scanned using the digital scanner Epson Expression 1480 (Epson (China) Co., Beijing, China) to analyze root total length, surface area, projective area, and tip numbers using the WinRHIZO software (Regent Instruments Inc., Quebec, QC, Canada). Root volume was measured in a graduated cylinder by the drainage method. The specific root length was calculated as root length divided by the root dry mass [40].

\subsubsection{Photosynthesis Measurement}

Net photosynthetic rates (Pn), stomatal conductance (Gs), transpiration rate (Tr), and carboxylation efficiency (CE) were determined on the fully expanded leaves using a portable open-flow gas exchange system LI-6400XT (LI-COR, Lincoln, NE, U.S.A) during the period from 9:30 to 11:30 am under natural sunlight and $\mathrm{CO}_{2}\left(400 \mu \mathrm{mol} \mathrm{mol}^{-1}\right)$ on a sunny day before harvest [41].

\subsubsection{Determination of Soil Enzymes}

The aerial parts of seedlings were removed after harvesting from the remaining three pots. Visible root materials with adhering soil were removed manually. Remaining soil samples used for analyzing enzymes activities were collected and sieved $(2 \mathrm{~mm})$ before analysis. The activities of urease (UE) and sucrase (SC) were determined by indophenol blue colorimetry and 3,5-dinitrosalicylic acid method, respectively [42]. Soil alkaline phosphatase (AKP) was determined by disodium phenylphosphate method [43]. Soil catalase (CAT) was determined by colorimetric method conducted by ultraviolet spectrophometry [44]. All enzymes activities were detected using soil enzyme kits according to the manufacturer's instructions (Comin Biotechnology Co., Ltd, Suzhou, China).

\subsection{Statistical Analysis}

The experimental data were log-transformed and then analyzed by the analysis of variance, and the comparison among treatment means was conducted using Tukey's test at the $5 \%$ level with the statistical software package SPSS 22.0 (SPSS for Windows, Version 22.0, Chicago, IL, USA). Non-transformed data appear in all figures, which were drawn by Sigma Plot version 10.0 (Systat Software Inc., Point Richmond, CA, USA).

\subsection{Estimation of Salt Tolerance and Soil Enzyme Activities}

Salt tolerance of Elaeagnus angustifolia L. seedlings and rhizospheric soil enzyme activities were evaluated by the subordinate function value (SFV) [45] combined with weights. The SFV was calculated using the Equation (1):

$$
U\left(X_{i j}\right)=\frac{X_{i j}-X_{j \min }}{X_{j \max }-X_{j \min }}
$$


where $U\left(X_{i j}\right)$ is the SFV of the index $(j)$ for the treatment $(i), X_{i j}$ is the actual measured value of the index $(j)$ for the treatment $(i)$, and $X_{j \max }$ and $X_{j \min }$ are the maximum and minimum values of the index (j) observed in the treatment (i).

The standard deviation coefficient method is used to determine the weight of different indexes. The coefficient of standard deviation $\left(V_{j}\right)$ and weight $\left(W_{j}\right)$ were evaluated via the following equations:

$$
\begin{gathered}
V_{j}=\sqrt{\sum_{j=1}^{n}\left(X_{i j}-\bar{X}_{j}\right)^{2}} / \bar{X}_{j} \\
W_{j}=V_{j} / \sum_{j=1}^{m} V_{j}
\end{gathered}
$$

where $X_{i j}$ is the actual measured value of the index $(j)$ for the treatment $(i), \bar{X}_{j}$ is the mean value of the index $(j)$. Finally, the plant salt tolerance and rhizospheric soil fertility of different treatments are expressed by the comprehensive evaluation value $(D)$. We then used Equation $(4)$ to calculate the comprehensive evaluation value $(D)$ :

$$
D=\sum_{j=1}^{n}\left(U\left(X_{j}\right) \times W_{j}\right)
$$

where $U\left(X_{j}\right)$ were the SFV of the index $(j) . D$ ranges from 0 to 1 .

\section{Results}

\subsection{Effects on Biomass Accumulation and Arbuscular Mycorrhizal Fungi (AMF) Colonization Rate}

Leaf and stem dry masses in the AMF treatment and co-microbial treatment were markedly higher than those in the control (Figure 3a,b). Microbial inoculations significantly increased root dry mass when compared with the control (Figure 3c). AMF colonization rates ranged from $5 \%$ in non-inoculated plants to $89.2 \%$ in single AMF-inoculated plants, and there are also significant differences between the three microbial treatments (Figure 3d).
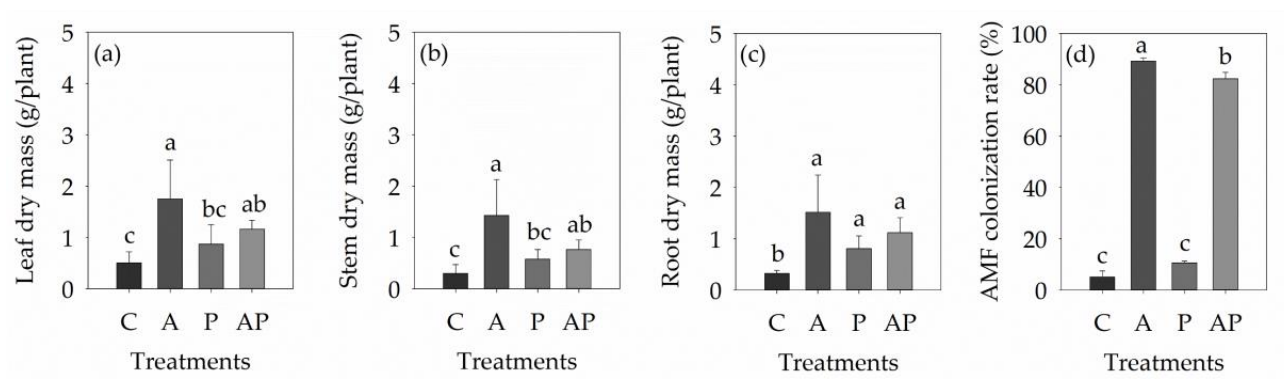

Figure 3. Effects of Glomus mosseae and Bacillus amyloliquefaciens on biomass and arbuscular mycorrhizal fungi (AMF) colonization rate of Elaeagnus angustifolia L. seedlings in saline soil. Values are the means \pm standard deviation of five replicates. Value sharing the different letters indicate significant differences between treatments at the 5\% level (Tukey's t-test). C: Control, A: AMF (Glomus mosseae) treatment, P: plant growth-promoting rhizobacteria (PGPR) (Bacillus amyloliquefaciens) treatment, AP: AMF + PGPR treatment. (a) leaf dry mass, (b) stem dry mass, (c) root dry mass, (d) AMF colonization rate.

\subsection{Effects on Morphological Characteristics of Aboveground Organs}

Leaf numbers and total leaf areas in three microbial treatments statistically increased, while specific stem length in microbial treatments significantly decreased in saline soil when compared with the control (Figure 4a,b,f). Only a single AMF inoculation significantly improved plant height when 
compared with the control, by $64 \%$ (Figure 4c). The presence of AMF, whether singly or combined with PGPR, statistically increased basal stem diameters and branch numbers when compared with the corresponding controls (Figure $4 \mathrm{~d}$,e). Both leaf succulence and stem succulence significantly decreased in single AMF-treated plants when compared to the control, by $28.04 \%$ and $27.72 \%$, respectively (Figure 4g,h).

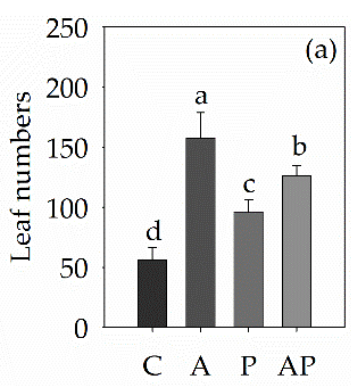

Treatments

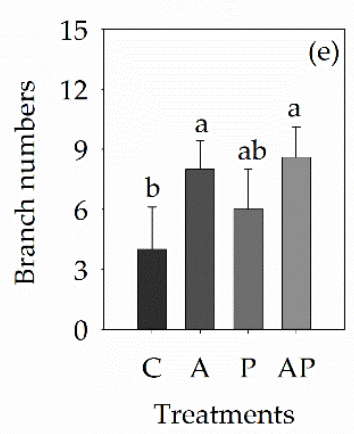

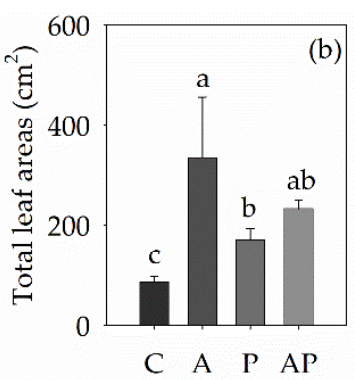

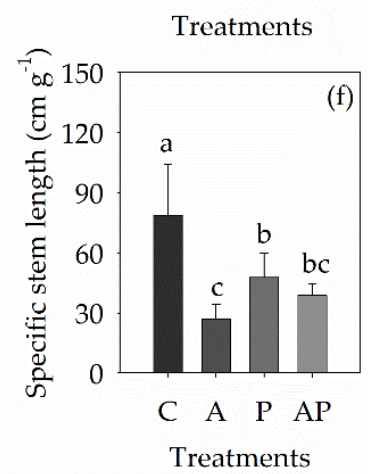

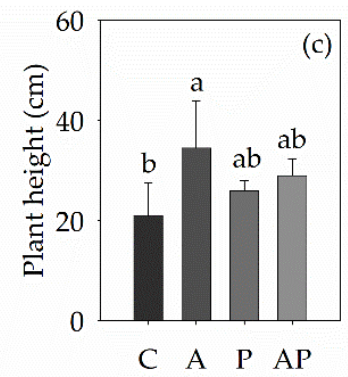

Treatments

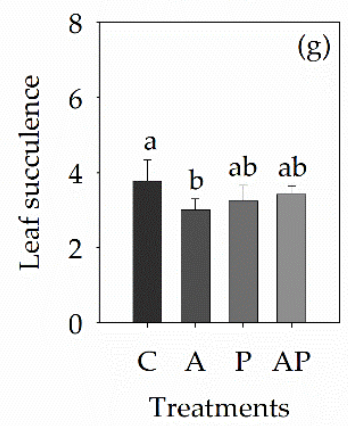

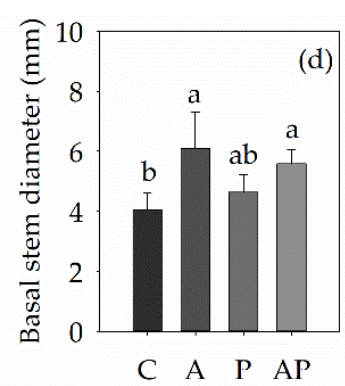

Treatments

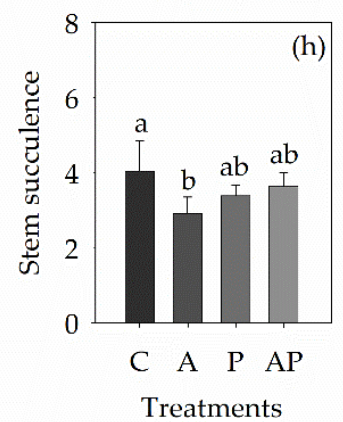

Figure 4. Effects of Glomus mosseae and Bacillus amyloliquefaciens on aboveground organ morphological characteristics of Elaeagnus angustifolia L. seedlings in saline soils. Values are the means \pm standard deviation of five replicates. Value sharing the different letters indicate significant differences between treatments at the 5\% level (Tukey's t-test). C: Control, A: AMF (Glomus mosseae) treatment, P: PGPR (Bacillus amyloliquefaciens) treatment, AP: AMF + PGPR treatment. (a) Leaf numbers, (b) total leaf areas, (c) plant height, (d) basal stem diameter, (e) branch numbers, (f) specific stem length, (g) leaf succulence, (h) stem succulence.

\subsection{Effects on Morphological Characteristics of Roots}

Root length significantly increased in the AMF treatment, by $43.89 \%$ when compared with the control, and was also markedly higher than that in the PGPR treatment (Figure 5a). Root surface area and root projected area in the PGPR treatments were considerably lower than those in the AMF treatment and co-microbial treatment (Figure $5 b, c)$. The presence of AMF, singly or combined with PGPR, significantly increased the root average diameters and root tip numbers (Figure $5 \mathrm{~d}, \mathrm{e}$ ). Compared to the control, all three microbial inoculations significantly increased root volumes (by 58.9-185.04\%) (Figure 5f), but markedly decreased specific root lengths (by 54.74-64.38\%) and root succulence (by $33.21-49.31 \%$ ) (Figure $5 g, h$ ). 

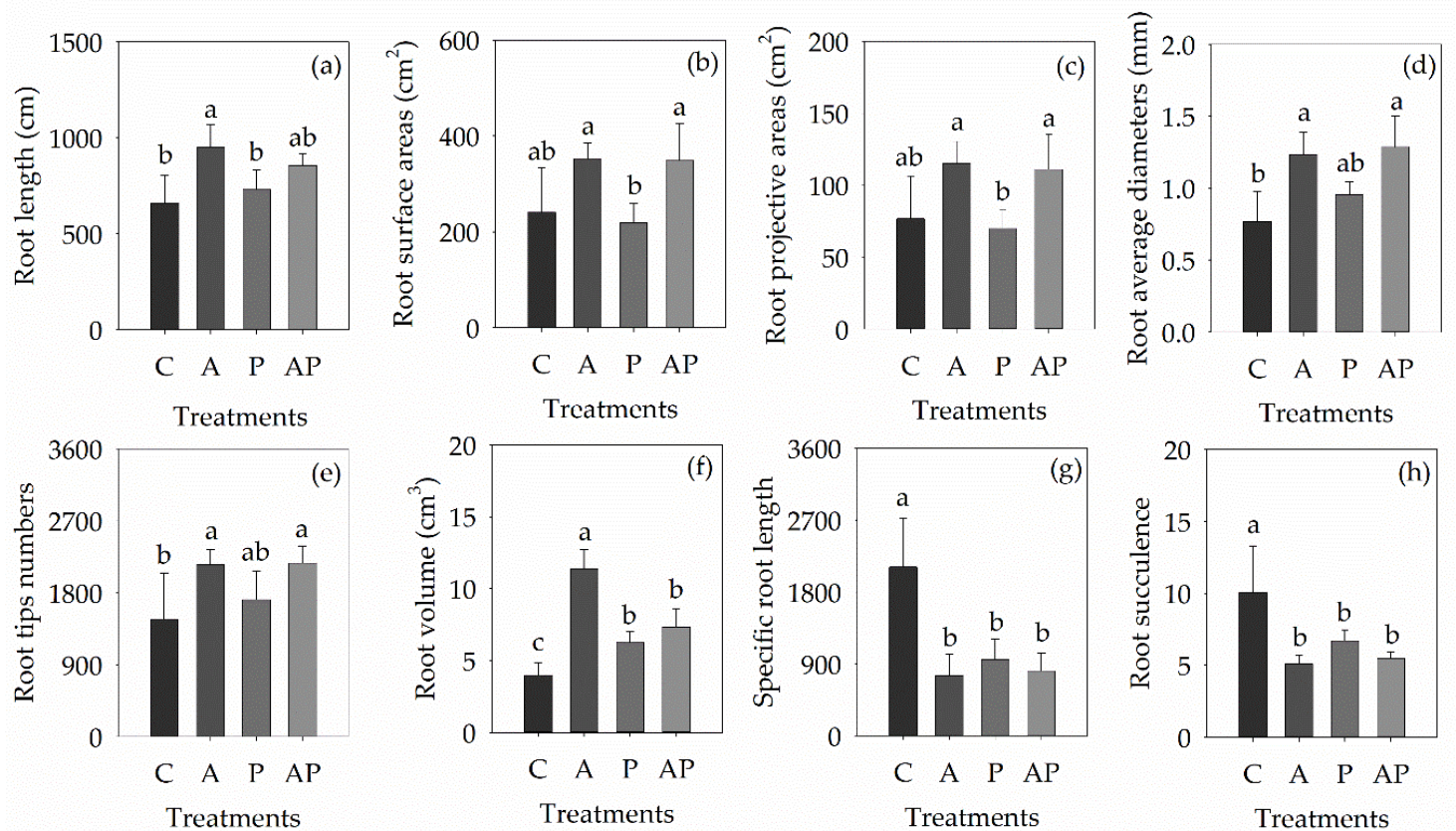

Figure 5. Effects of Glomus mosseae and Bacillus amyloliquefaciens on root morphological characteristics of Elaeagnus angustifolia L. seedlings in saline soils. Values are the means \pm standard deviation of five replicates. Value sharing the different letters indicate significant differences between treatments at the 5\% level (Tukey's t-test). C: Control, A: AMF (Glomus mosseae) treatment, P: PGPR (Bacillus amyloliquefaciens) treatment, AP: AMF + PGPR treatment. (a) root length, (b) root surface areas, (c) root projective areas, (d) root average diameters, (e) root tips numbers, (f) root volume, (g) specific root length, (h) root succulence.

\subsection{Effects on Photosynthesis}

Pn and Gs in three microbial treatments significantly increased when compared with the corresponding controls under saline soil conditions, and significant differences were evident among the three microbial-inoculated treatments (Figure $6 a, c$ ). The presence of AMF, whether singly or combined with PGPR, statistically increased $\operatorname{Tr}$ (Figure 6b). CE only significantly increased in the AMF treatment when compared with control, by $40.84 \%$. CE in the AMF treatment was also significantly higher than that in the PGPR treatment and co-microbial treatment, by $40.69 \%$ and $29.82 \%$, respectively (Figure $6 \mathrm{~d}$ ).
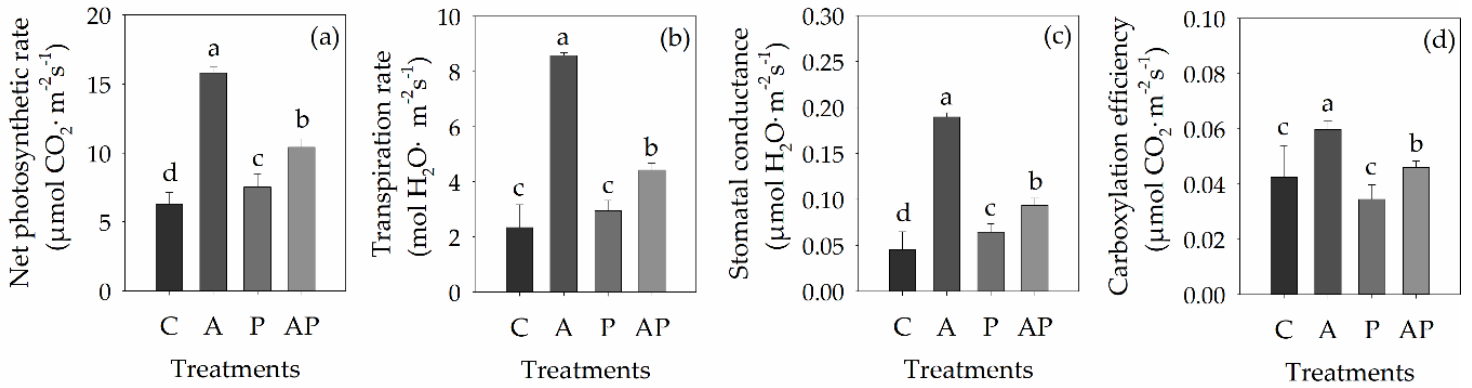

Figure 6. Effects of Glomus mosseae and Bacillus amyloliquefaciens on photosynthetic parameters of Elaeagnus angustifolia L. seedlings in saline soils. Values are the means \pm standard deviation of five replicates. Value sharing the different letters indicate significant differences between treatments at the 5\% level (Tukey's t-test). C: Control, A: AMF (Glomus mosseae) treatment, P: PGPR (Bacillus amyloliquefaciens) treatment, AP: AMF + PGPR treatment. (a) net photosynthetic rate, (b) transpiration rate, (c) stomatal conductance, (d) carboxylation efficiency. 


\subsection{Effects on Soil Enzymes}

The CAT in the rhizosphere soils only significantly increased in the AMF treatment (Figure 7a). AMF inoculation, singly or combined with PGPR, significantly increased AKP in the rhizosphere soil, by an average of $12.86 \%$ when compared to the control (Figure $7 \mathrm{~b}$ ). A significant increase of UE was only found in the single AMF inoculation, by $36.01 \%$ (Figure 7c). Compared to the control, SC increased by $27.41 \%$ and $53.28 \%$ in the AMF treatment and co-microbial treatment, respectively (Figure $7 \mathrm{~d}$ ).
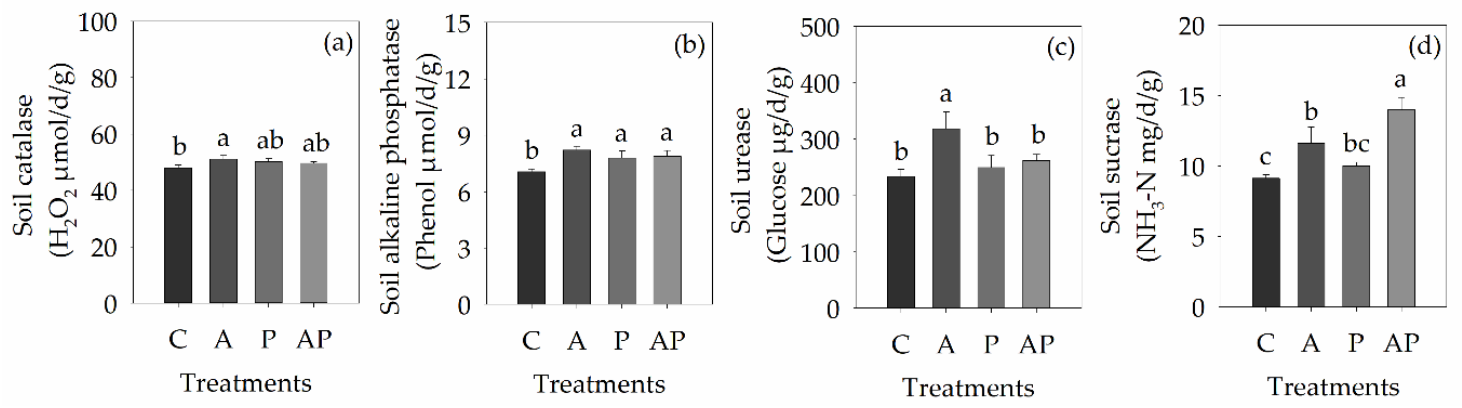

Figure 7. Effects of Glomus mosseae and Bacillus amyloliquefaciens on photosynthetic parameters of Elaeagnus angustifolia L. seedlings in saline soils. Values are the means \pm standard deviation of three replicates. Value sharing the different letters indicate significant differences between treatments at the 5\% level (Tukey's t-test). C: Control, A: AMF (Glomus mosseae) treatment, P: PGPR (Bacillus amyloliquefaciens) treatment, AP: AMF + PGPR treatment. (a) soil catalase, (b) soil alkaline phosphatase, (c) soil urease, (d) soil sucrase.

\subsection{Salt Tolerance Assessment}

Based on the ranking of SFVs of 18 parameters, the AMF treatment had the highest SFV and control had the lowest. The salt tolerance ranking of different treatments was AMF treatment $>$ AMF and PGPR treatment $>$ PGPR treatment $>$ control (Table 1).

Table 1. Salt tolerance assessment of Elaeagnus angustifolia L. under different treatments using the subordinate function value method.

\begin{tabular}{cccccc}
\hline Parameters & $\mathbf{C}$ & $\mathbf{A}$ & $\mathbf{P}$ & $\mathbf{A P}$ & $\boldsymbol{W}$ \\
\hline LDM & 0 & 1 & 0.2953 & 0.53 & 0.0737 \\
SDM & 0 & 1 & 0.2452 & 0.4141 & 0.094 \\
RDM & 0 & 1 & 0.4084 & 0.6642 & 0.0803 \\
BN & 0 & 0.8696 & 0.4348 & 1 & 0.047 \\
BSD & 0 & 1 & 0.2873 & 0.7562 & 0.0269 \\
PH & 0 & 1 & 0.3661 & 0.5923 & 0.0306 \\
LN & 0 & 1 & 0.3933 & 0.6917 & 0.0594 \\
TLA & 0 & 1 & 0.3384 & 0.5892 & 0.0761 \\
RL & 0 & 1 & 0.2436 & 0.6783 & 0.0243 \\
RPA & 0.1513 & 1 & 0 & 0.9095 & 0.0375 \\
RSA & 0.1625 & 1 & 0 & 0.9765 & 0.0363 \\
RAD & 0 & 0.8962 & 0.3538 & 1 & 0.0345 \\
RV & 0 & 1 & 0.3047 & 0.4537 & 0.064 \\
RTN & 0 & 0.9729 & 0.3531 & 1 & 0.0274 \\
Pn & 0 & 1 & 0.1293 & 0.4327 & 0.0633 \\
Gs & 0 & 1 & 0.1325 & 0.3356 & 0.0977 \\
Tr & 0 & 1 & 0.0974 & 0.3323 & 0.0922 \\
CE & 0.6827 & 1 & 0 & 0.4585 & 0.0347 \\
D & 0.035262 & 0.989448 & 0.243499 & 0.586412 & 2 \\
Sequence & 4 & 1 & 3 & 2 &
\end{tabular}

Note: C: Control, A: AMF (Glomus mosseae) treatment, P: PGPR (Bacillus amyloliquefaciens) treatment, LDM: leaf dry mass, SDM: stem dry mass, RDM: root dry mass, BN: brunch number, BSD: basal stem diameter, PH: plant height, LN: leaf numbers, TLA: total leaf area, RL: root length, RPA: root projective area, RSA: root surface area, RD: root diameter, RV: root volume, RTN: root tips number, Pn: net photosynthetic capacity, Gs: gas conductance, Tr: transpiration rate, CE: carboxylation efficiency, D: comprehensive evaluation value, W: weight. 


\subsection{Soil Fertility Assessment}

We used the SFV method to evaluate the soil fertility in the rhizosphere of Elaeagnus angustifolia L. seedlings in saline soils. Based on the ranking of SFVs, the soil enzymes ranking was AMF treatment $>$ co-microbial treatment $>$ PGPR treatment $>$ control (Table 2).

Table 2. Soil fertility assessment in the rhizosphere of Elaeagnus angustifolia L. seedlings under different treatments using the subordinate function value method.

\begin{tabular}{cccccc}
\hline Treatment & C & A & P & AP & W \\
\hline CAT & 0 & 1 & 0.6989 & 0.5223 & 0.064 \\
AKP & 0 & 1 & 0.6345 & 0.7171 & 0.1514 \\
SC & 0 & 0.5144 & 0.1817 & 1 & 0.3289 \\
UE & 0 & 1 & 0.1885 & 0.3396 & 0.4556 \\
D & 0 & 0.8402 & 0.2864 & 0.6256 & \\
Sequence & 4 & 1 & 3 & 2 & \\
\hline
\end{tabular}

Note: C: Control, A: AMF (Glomus mosseae) treatment, P: PGPR (Bacillus amyloliquefaciens) treatment, AP: AMF + PGPR treatment, CAT: Soil catalase, AKP: Soil alkaline phosphatase, SC: Soil sucrase, UE: Soil urease, D: comprehensive evaluation value, $W$ : weight.

\section{Discussion}

Soil salinity induces adverse effects on seedling establishment and biomass accumulation $[1,46]$. Although halophytes possess inherent salt-tolerant strategies, excessive soil salinity could damage seedling establishment and further inhibit growth in halophytes [47]. Soil microbes are of pivotal importance for plant growth, especially in adverse ecosystems such as those with saline soil conditions [48]. Previous studies reported that AMF and PGPR inoculations could reduce biomass losses induced by soil salinity, and that co-microbial inoculation performed better than single AMF or PGPR inoculations [49-52]. In contrast, the results in this study show that the single AMF inoculation promoted significantly greater biomass accumulation and AMF colonization rate than that in the non-inoculated control, and was even slightly greater than that in the co-microbial inoculation (albeit there was no statistical difference) (Figure 3). Thus, Elaeagnus angustifolia L. seedlings are more responsive to the specific AMF than to overall microbial richness or diversity in saline soils. Therefore, key specific microbial species, not the microbial richness or diversity, determined biomass accumulation in our study [53].

The Bacillus amyloliquefaciens FZB42 strain was used in this experiment as the PGPR inoculum. Previous studies showed that FZB42 could stimulate fresh and dry mass accumulation and induce systemic salt tolerance of Arabidopsis thaliana under $100 \mathrm{mM} \mathrm{NaCl}$ hydroponic culture conditions [33]. However, FZB42 was only effective in improving root biomass accumulation and salt tolerance of Elaeagnus angustifolia L. seedlings in the present study under saline soil conditions (Figure 3, Table 1). Hence, individual microbe species vary greatly in their effect on different plant species in different growth conditions. Moreover, both positive and negative effects of PGPR in plants have been reported in previous publications [54-56]. Hence, we suggest that PGPR efficiency of different plants may be influenced either by the growth environment or by the existence of "functional specificity" in the combination of plant and microbe species [48].

The growth and development of halophytes under saline conditions are inseparable from their own adaptive mechanisms, in which the adaptions of their morphological characteristics are the most intuitive [57]. The plant has to adjust its physiological functions and morphological characteristics in the leaf, stem and root to adapt to adverse environments as well as to ensure survival $[37,58,59]$. Root systems are the first "line of defense" to encounter saline soil, and root-system indicators are often used to quantify the acquisition capacity of water and nutrients in plants [60]. Soil salinity directly influenced root growth $[57,59]$. Previous studies have documented that AMF and PGPR colonization modulated the root-system architecture and reversed salinity effects on agricultural production both quantitatively and qualitatively in salt-sensitive plants such as soybean, citrus, and 
maize $[26,40,59,61,62]$. The present investigation showed that AMF inoculation, singly or mixed with PGPR, significantly increased root biomass, length, surface area, average diameter, and tips number of Elaeagnus angustifolia L. seedlings when compared to control and PGPR inoculation (Figures 3 and 5). The root volumes in AMF inoculated seedlings were significantly higher than those in PGPR inoculated seedlings (Figure 5f), which indicates that Elaeagnus angustifolia L. seedlings are more responsive to AMF inoculation than to PGPR inoculation in saline soils.

Generally, a higher specific root length indicates higher root hydraulic conductivity and proliferation rate [57]. Root succulence is an adaptive mechanism to improve salt tolerance by diluting salt content in plants [63]. Our results confirmed that microbial inoculation significantly decreased specific root length and root succulence in Elaeagnus angustifolia L. seedlings when compared to the control (Figure 5g,h). It is possible that AMF hyphae replace the absorption function of roots, and that specific compounds exuded from PGPR and AMF provide more nutrients and exclude toxic ions from the rhizosphere, allowing the host to develop thicker roots and a larger absorption area $[59,64,65]$. Thus, Elaeagnus angustifolia L. seedlings with AMF and PGPR inoculation did not require greater specific root lengths, either as a surrogate for diameter to obtain more resources [66], or as an adaptive mechanism to compensate for loss of root biomass under osmotic stress induced by salinity $[57,59]$. Furthermore, Elaeagnus angustifolia L. seedlings with AMF and PGPR inoculations also had no requirement for a greater root succulence to reduce the damage caused by toxic ions [63].

The optimization of root morphology facilitated the transmission of soil water and nutrients to the stems, branches and leaves, which benefits the growth of aboveground organs [58]. Stems not only transport water and nutrients from the roots but also bear the full weight of aboveground tissues and provide growth spaces for branches and leaves [58]. Salinity stress suppresses stem and branch growth [67]. In this study, we found that stem biomass, plant height, stem diameter, and branch numbers in Elaeagnus angustifolia L. were increased markedly by the presence of AMF (Figures 3 and 4), consistent with previous reports on citrus, fenugreek and trifoliate orange $[62,67,68]$. However, the specific stem length in Elaeagnus angustifolia L. decreased significantly in three microbial treatments (Figure 4f). This result may be interpreted as AMF and PGPR reversing the salinity effects on stems and branches, such that Elaeagnus angustifolia L. with microbial inoculation did not require a greater specific stem length to ensure the effectiveness of associated functions. Hence, we suggest that increasing specific stem length may be one of the self-adaptive mechanisms used by Elaeagnus angustifolia $\mathrm{L}$. without microbial inoculation to counter adverse salt stress conditions.

As well as the growth of stems and branches, we found that leaf biomass, leaf numbers, and leaf total areas in Elaeagnus angustifolia L. seedlings also increased with the presence of AMF (Figures 3 and 4). This result indicates that AMF and PGPR could reduce salt damage on leaves and promote the growth and surface expansion of leaves in Elaeagnus angustifolia L. seedlings under saline soil conditions, which is also consistent with studies of citrus [69], alfalfa [70], and beans [71] inoculated with AMF under salt stress conditions. Similar to the results of root succulence, microbial inoculation decreased the succulence of leaf and stem (albeit the differences were significant only in the single AMF inoculation) (Figures 4 and 5). Succulence is an anatomical adaption to permit the water accumulated in leaves, stems and roots to dissolve salt ions [57]. For Elaeagnus angustifolia L. with microbial inoculation, both the promotion of root biomass and the optimization of root morphology synthetically reduced the translation of salt ions to aerial organs, thereby mitigating the impact of toxic ions; consequently, the plants did not need to employ the succulence strategy to mediate salt stress. Meanwhile, the succulence level in root is higher than that in stem and leaf (Figures 4 and 5) and indicating that Elaeagnus angustifolia L. mainly relies on root succulence to increase salt tolerance [63].

Leaves, together with the stems and branches, are the carbon-fixing organs in halophytes [58,72]. Salinity stress stunts the growth of leaves, stems and branches [73], further impairing photosynthetic capacity $[1,3,67,74]$. Our findings provide further support for this view and showed that Elaeagnus angustifolia L. inoculated with AMF separately, or together with PGPR, had markedly higher Pn, Gs, Tr, and CE when compared to the control under salt stress (Figure 6), which is necessary to guarantee 
the photosynthesis, transpiration, $\mathrm{CO}_{2}$ assimilation and gas exchange capacity [75]. These results are also consistent with other AMF-inoculated plant species, such as citrus [62], Leymus chinensis [76], and black locust [77]. The enhancement of photosynthesis may be caused by 1) growth promotion in the leaf and stem, which improves light interception and utility, and further benefits the photosynthetic capacity [28], 2) the optimization of the root structure, which is beneficial to the absorption of water and nutrients (such as nitrogen and magnesium), further promoting photosynthesis [24], and 3) combined enhancements in both gas exchange capacity and $\mathrm{CO}_{2}$ diffusion speed are instrumental in photosynthesis [78].

The result of SFVs including 21 plant parameters showed that the salt tolerance of Elaeagnus angustifolia L. seedlings with AMF inoculation was higher than that in co-microbial inoculation and PGPR inoculation (Table 1). This confirmed that AMF inoculation enhances salt tolerance of Elaeagnus angustifolia L. seedlings, and that Elaeagnus angustifolia L. seedlings are more responsive to AMF inoculation than co-microbial inoculation and PGPR inoculation in saline soils. Therefore, key specific microbial species, not the microbial richness and diversity, determined the salt tolerance of one-year old Elaeagnus angustifolia L. seedlings in saline soil in this study [53]. Previous results showed that the plant growth-promoting effects induced by different microbial inoculations varied markedly between different growth stages and also depended on the combination of host and microbes [79]. In this study, we just measured the relevant parameters in the seedling stages of Elaeagnus angustifolia L. A significant hurdle remains in addressing both the longevity of the microbial inoculum in the rhizosphere and the duration of plant growth-promoting effects induced by the interactions between halophytes and microbes. This aspect needs further study in the future.

Plant growth is inseparable from leaf photosynthesis and nutrient absorption by roots. Changes in soil nutrients are further closely related to soil enzyme activities. As key indicators of soil fertility levels, soil enzyme activities play a potentially important role in biochemical reactions of soil [28]. AKP indicates the level of phosphorus in soil; UE participates in soil $\mathrm{N}$ cycling; SC can increase soluble nutrients in soil; CAT can prevent the toxic effects of hydrogen peroxide on plants. However, the soil enzyme activities, such as CAT, AKP, SC, and UE, are inhibited by salinity [20] due to the inhibitory effect of salt on enzyme proteins through the disruption of the tertiary protein structure $[28,80]$. We found that the activities of four soil enzymes all significantly increased in AMF treatments, both AKP and SC markedly increased in co-microbial inoculation, and only AKP significantly increased in PGPR treatments (Figure 7), which indicates that the effects of microbial inoculation on soil enzyme activities are enzyme-specific. Soil enzymes in the rhizosphere are most affected by AMF inoculation in terms of the measured parameters.

SFVs results show the soil enzyme activities in the AMF inoculation are higher than those in the co-microbial inoculation and PGPR inoculation, and the SFVs of soil enzyme activities is lowest in the control (Table 2). Thus, microbial inoculation can effectively promote soil enzyme activities in the rhizosphere. One possible explanation could be that the hyphal effect of AMF, the exudation of specific compounds from PGPR, and the growth promotion of roots together contribute to stimulated microbial activity and modify nutritional status in the rhizosphere under salt stress conditions $[20,53,65,81]$. The enhanced activities of enzymes, such as AKP and UE, could benefit the transformation of soil nutrients (such as phosphorus and nitrogen) and further further promotes the overall availability of soil nutrients. Therefore, the efforts of soil enzymes are conducive to the benign development of the soil microenvironment in this study.

\section{Conclusions}

Here, we observed that inoculation of Elaeagnus angustifolia L. with G. mosseae singly or synthetically with FZB42 mitigated the adverse effects of salt stress on biomass accumulation. The presence of AMF could promote root growth and modify root architecture, which may be conducive to the activities of soil enzymes and further boost nutrient acquisition. AMF inoculation also enhanced growth performance in leaves and stems, benefitting the interception and absorption of light and thus 
maximizing photosynthesis, transpiration, $\mathrm{CO}_{2}$ assimilation and gas exchange capacity of Elaeagnus angustifolia L. in saline soil conditions. One-year-old Elaeagnus angustifolia L. seedlings are more responsive to the inoculation of special AMF identity per se than a combination of AMF and PGPR as well as single PGPR inoculation in saline soils. These results suggest that Glomus mosseae can be used in saline soil as a biotic elicits to stimulate Elaeagnus angustifolia L. growth and improve soil enzymes. Hence, selection of suitable microorganism inoculums is an important step before initiating any inoculation program, and could be beneficial in the recovery of saline-degraded areas.

Author Contributions: Conceptualization, J.P. and X.X.; Formal analysis, J.P. and W.Z.; Funding acquisition, C.H. and S.M.; Methodology, J.P., C.H., W.Z., and J.L.; Software, J.P. and W.Z.; Visualization, J.P., and W.Z.; Writing-original draft, J.P. and X.X.; Writing—review and editing, C.H., F.P., S.M., and X.X. All authors have read and agreed to the published version of the manuscript.

Funding: This research was funded by National Key Research and Development Program of China (No. 2017YFE0119100).

Acknowledgments: We would like to acknowledge Pro. Ruoyu Wang for his donation of the Bacillus amyloliquefaciens FZB42 strain and assistance in this manuscript.

Conflicts of Interest: The authors declare no conflict of interest.

\section{References}

1. Munns, R.; Tester, M. Mechanisms of salinity tolerance. Annu. Rev. Plant Biol. 2008, 59, 651-681. [CrossRef] [PubMed]

2. Estrada, B.; Aroca, R.; Azcón-Aguilar, C.; Barea, J.M.; Ruiz-Lozano, J.M. Importance of native arbuscular mycorrhizal inoculation in the halophyte Asteriscus maritimus for successful establishment and growth under saline conditions. Plant Soil 2013, 370, 175-185. [CrossRef]

3. Chaves, M.M.; Flexas, J.; Pinheiro, C. Photosynthesis under drought and salt stress: Regulation mechanisms from whole plant to cell. Ann. Bot. 2009, 103, 551-560. [CrossRef] [PubMed]

4. Munns, R.; Gilliham, M. Salinity tolerance of crops-What is the cost? New Phytol. 2015, 208, 668-673. [CrossRef]

5. Kosová, K.; Vítámvás, P.; Urban, M.O.; Prášil, I.T. Plant proteome responses to salinity stress-comparison of glycophytes and halophytes. Funct. Plant Biol. 2013, 40, 775-786. [CrossRef]

6. Habiba, U.; Anwarul, A.M.; Shaw, R.; Hassan, A.W.R. Salinity-Induced Livelihood Stress in Coastal Region of Bangladesh. In Community, Environment and Disaster Risk; Emerald Publishers: Bingley, UK, 2013.

7. Anik, A.R.; Ranjan, R.; Ranganathan, T. Estimating the impact of salinity stress on livelihood choices and incomes in Rural Bangladesh. J. Int. Dev. 2018, 30, 1414-1438. [CrossRef]

8. Rubin, R.L.; van Groenigen, K.J.; Hungate, B.A. Plant growth promoting rhizobacteria are more effective under drought: A meta-analysis. Plant Soil 2017, 416, 309-323. [CrossRef]

9. Ilangumaran, G.; Smith, D.L. Plant growth promoting rhizobacteria in amelioration of salinity stress: A systems biology perspective. Front. Plant Sci. 2017, 8, 1768. [CrossRef]

10. Chandrasekaran, M.; Boughattas, S.; Hu, S.; Oh, S.-H.; Sa, T. A meta-analysis of arbuscular mycorrhizal effects on plants grown under salt stress. Mycorrhiza 2014, 24, 611-625. [CrossRef]

11. Qian, T.; Tsunekawa, A.; Peng, F.; Masunaga, T.; Wang, T.; Li, R. Derivation of salt content in salinized soil from hyperspectral reflectance data: A case study at Minqin Oasis, Northwest China. J. Arid Land 2019, 11, 111-122. [CrossRef]

12. Huang, C.H.; Zong, L.; Buonanno, M.; Xue, X.; Wang, T.; Tedeschi, A. Impact of saline water irrigation on yield and quality of melon (Cucumis melo cv. Huanghemi) in northwest China. Eur. J. Agron. 2012, 43, 68-76. [CrossRef]

13. Tedeschi, A.; Zong, L.; Huang, C.H.; Vitale, L.; Volpe, M.G.; Xue, X. Effect of salinity on growth parameters, soil water potential and ion composition in Cucumis melo cv. Huanghemi in North-Western China. J. Agron. Crop Sci. 2016, 203, 41-55. [CrossRef]

14. Hui, H.; Tong, Q.; Feng, Z.D.; Chen, X.; Huang, A.; Youhao, E.; Gao, W. Study on salt land changes in Minqin Oasis, Northwest China. Proc. SPIE 2006, 6199. [CrossRef] 
15. Qian, T.; Tsunekawa, A.; Masunaga, T.; Wang, T. Analysis of the spatial variation of soil salinity and its causal factors in China's Minqin Oasis. Math. Probl. Eng. 2017, 2, 1-9. [CrossRef]

16. Liu, Z.; Zhu, J.; Yang, X.; Wu, H.; Wei, Q.; Wei, H.; Zhang, H. Growth performance, organ-level ionic relations and organic osmoregulation of Elaeagnus angustifolia in response to salt stress. PLoS ONE 2018, 13, e0191552. [CrossRef] [PubMed]

17. Farzaei, M.H.; Bahramsoltani, R.; Abbasabadi, Z.; Rahimi, R. A comprehensive review on phytochemical and pharmacological aspects of Elaeagnus angustifolia L. J. Pharm. Pharmacol. 2015, 67, 1467-1480. [CrossRef]

18. Liu, H.; Wang, Y.; Tang, M. Arbuscular mycorrhizal fungi diversity associated with two halophytes Lycium barbarum L. and Elaeagnus angustifolia L. in Ningxia, China. Arch. Agron. Soil Sci. 2017, 63, 796-806. [CrossRef]

19. Zhang, H.; Wu, X.; Li, G.; Qin, P. Interactions between arbuscular mycorrhizal fungi and phosphate-solubilizing fungus (Mortierella sp.) and their effects on Kostelelzkya virginica growth and enzyme activities of rhizosphere and bulk soils at different salinities. Biol. Fertil. Soils 2011, 47, 543-554. [CrossRef]

20. Folli-Pereira, M.D.S.; Meira-Haddad, L.S.A.; Kasuya, M.C.M. Plant-microorganism interactions: Effects on the tolerance of plants to biotic and abiotic stresses. In Crop Improvement: New Approaches and Modern Techniques; Springer: Berlin, Germany, 2013; pp. 209-239.

21. Yang, X.; Yu, H.; Zhang, T.; Guo, J.; Zhang, X. Arbuscular mycorrhizal fungi improve the antioxidative response and the seed production of Suaedoideae species Suaeda physophora Pall. under salt stress. Not. Bot. Horti Agrobot. Cluj-Napoca 2016, 44, 533-540. [CrossRef]

22. Puente, E.O.R.; Prabhaharan, R.; Amador, B.M.; Espinoza, F.R.; Puente, M.; Cepeda, R.D.V. Ameliorative effects of salt resistance on physiological parameters in the halophyte Salicornia bigelovii torr. with plant growth-promoting rhizobacteria. Afr. J. Biotechnol. 2013, 12, 5278-5284.

23. Bharti, N.; Barnawal, D.; Maji, D.; Kalra, A. Halotolerant PGPRs prevent major shifts in indigenous microbial community structure under salinity stress. Microb. Ecol. 2015, 70, 196-208. [CrossRef] [PubMed]

24. Pan, J.; Peng, F.; Xue, X.; You, Q.; Zhang, W.; Wang, T.; Huang, C. The growth promotion of two salt-tolerant plant groups with PGPR inoculation: A meta-analysis. Sustainability 2019, 11, 378. [CrossRef]

25. Chandrasekaran, M.; Chanratana, M.; Kim, K.; Seshadri, S.; Sa, T. Impact of arbuscular mycorrhizal fungi on photosynthesis, water status, and gas exchange of plants under salt stress-A meta-analysis. Front. Plant Sci. 2019, 16, 457. [CrossRef] [PubMed]

26. Egamberdieva, D.; Wirth, S.; Jabborova, D.; Räsänen, L.A.; Liao, H. Coordination between Bradyrhizobium and Pseudomonas alleviates salt stress in soybean through altering root system architecture. J. Plant Interact. 2017, 12, 100-107. [CrossRef]

27. Ghazanfar, B.; Cheng, Z.; Cuinan, W.U.; Liu, H.; Hezi, L.I.; Rehman, R.N.U.; Ahmad, I.; Khan, A.R. Glomus etunicatum root inoculation and foliar application of acetyl salicylic acid induced $\mathrm{NaCl}$ tolerance by regulation of $\mathrm{NaCl} \&$ LeNHXL gene expression and improved photosynthetic performance in tomato seedlings. Pak. J. Bot. 2016, 48, 1209-12117.

28. Islam, F.; Yasmeen, T.; Arif, M.S.; Ali, S.; Ali, B.; Hameed, S.; Zhou, W. Plant growth promoting bacteria confer salt tolerance in Vigna radiata by up-regulating antioxidant defense and biological soil fertility. Plant Growth Regul. 2016, 80, 23-36. [CrossRef]

29. Xun, F.; Xie, B.; Liu, S.; Guo, C. Effect of plant growth-promoting bacteria (PGPR) and arbuscular mycorrhizal fungi (AMF) inoculation on oats in saline-alkali soil contaminated by petroleum to enhance phytoremediation. Environ. Sci. Pollut. Res. 2015, 22, 598-608. [CrossRef]

30. Gong, Z.; Zhang, G.; Chen, Z. Development of Soil Classification in China. In Soil Classification: A Global Desk Reference; Eswaran, H., Ahrens, R., Rice, T.J., Stewart, B.A., Eds.; CRC Press: Boca Raton, FL, USA, 2003; pp. 101-127.

31. Soil Survey Staff, USDA. Soil Taxonomy: A Basic System of Soil Classification for Making and Interpreting Soil Surveys, 2nd ed.; Natural Resource Conservation Service, Agricultural Handbook No. 436; U.S. Government Printing Office: Washington, DC, USA, 1999; pp. 414-417.

32. Garg, N.; Chandel, S. The effects of salinity on nitrogen fixation and trehalose metabolism in mycorrhizal Cajanus cajan (L.) Mill sp. Plants. J. Plant Growth Regul. 2011, 30, 490-503. [CrossRef]

33. Liu, S.; Hao, H.; Lu, X.; Zhao, X.; Wang, Y.; Zhang, Y.; Xie, Z.; Wang, R. Transcriptome profiling of genes involved in induced systemic salt tolerance conferred by Bacillus amyloliquefaciens FZB42 in Arabidopsis thaliana. Sci. Rep. 2017, 7, 1-13. [CrossRef] 
34. Hao, H.-T.; Zhao, X.; Shang, Q.-H.; Wang, Y.; Guo, Z.-H.; Zhang, Y.-B.; Xie, Z.-K.; Wang, R.-Y. Comparative digital gene expression analysis of the Arabidopsis response to volatiles emitted by Bacillus amyloliquefaciens. PLoS ONE 2016, 11, e0158621. [CrossRef]

35. Weremijewicz, J.; Janos, D.P. Arbuscular common mycorrhizal networks mediate intra- and interspecific interactions of two prairie grasses. Mycorrhiza 2018, 28, 71-83. [CrossRef] [PubMed]

36. Qi, C.-H.; Chen, M.; Song, J.; Wanga, B.S. Increase in aquaporin activity is involved in leaf succulence of the euhalophyte Suaeda salsa under salinity. Plant Sci. 2009, 176, 200-205. [CrossRef]

37. Han, Y.; Wang, W.; Sun, J.; Ding, M.; Zhao, R.; Deng, S.; Wang, F.; Hu, Y.; Wang, Y.; Lu, Y.; et al. Populus euphratica XTH overexpression enhances salinity tolerance by the development of leaf succulence in transgenic tobacco plants. J. Exp. Bot. 2013, 64, 4225-4238. [CrossRef] [PubMed]

38. Poorter, H.; Ryser, P. The limits to leaf and root plasticity: What is so special about specific root length? New Phytol. 2015, 206, 1188-1190. [CrossRef] [PubMed]

39. Giovannetti, M.; Mosse, B. An evaluation of techniques for measuring vesicular arbuscular mycorrhizal infection in roots. New Phytol. 1980, 84, 489-500. [CrossRef]

40. Sheng, M.; Tang, M.; Chen, H.; Yang, B.; Zhang, F.; Huang, Y. Influence of arbuscular mycorrhizae on the root system of maize plants under salt stress. Rev. Can. Microbiol. 2009, 55, 879-886. [CrossRef] [PubMed]

41. Luo, J.; Huang, C.; Peng, F.; Xue, X.; Wang, T. Effect of salt stress on photosynthesis and related physiological characteristics of Lycium ruthenicum Murr. Acta Agric. Scand. Sect. B Soil Plant Sci. 2017, 67, 680-692. [CrossRef]

42. Liu, Y.; Zhao, L.; Wang, Z.; Liu, L.; Zhang, P.; Sun, J.; Wang, B.; Song, G.; Li, X. Changes in functional gene structure and metabolic potential of the microbial community in biological soil crusts along a revegetation chronosequence in the tengger desert. Soil Biol. Biochem. 2018, 126, 40-48. [CrossRef]

43. Kandeler, E.; Tscherko, D.; Spiegel, H. Long-term monitoring of microbial biomass, N mineralization and enzyme activities of a Chernozem under different tillage management. Biol. Fertil. Soils 1999, 28, 343-351. [CrossRef]

44. Trasar-Cepeda, C.; Camiña, F.; Leirós, M.C.; Gil-Sotres, F. An improved method to measure catalase activity in soils. Soil Biol. Biochem. 1999, 31, 483-485. [CrossRef]

45. Huang, K.; Dai, X.; Xu, Y.; Dang, S.; Shi, T.; Sun, J.; Wang, K. Relation between level of autumn dormancy and salt tolerance in lucerne (Medicago sativa). Crop Pasture Sci. 2018, 69, 194-204. [CrossRef]

46. Munns, R. Comparative physiology of salt and water stress. Plant Cell Environ. 2002, 25, 239-250. [CrossRef] [PubMed]

47. Himabindu, Y.; Chakradhar, T.; Reddy, M.C.; Kanygin, A.; Redding, K.E.; Chandrasekhar, T. Salt-tolerant genes from halophytes are potential key players of salt tolerance in glycophytes. Environ. Exp. Bot. 2016, 124, 39-63. [CrossRef]

48. Heijden, M.G.A.V.D.; Bardgett, R.D.; Straalen, N.M.V. The unseen majority: Soil microbes as drivers of plant diversity and productivity in terrestrial ecosystems. Ecol. Lett. 2008, 11, 296-310. [CrossRef]

49. Kumar, A.; Sharma, S.; Mishra, S. Effect of alkalinity on growth performance of Jatropha curcas inoculated with PGPR and AM fungi. J. Phycol. 2009, 3, 177-184.

50. Hidri, R.; Barea, J.M.; Mahmoud, M.B.; Abdelly, C.; Azcón, R. Impact of microbial inoculation on biomass accumulation by Sulla carnosa provenances, and in regulating nutrition, physiological and antioxidant activities of this species under non-saline and saline conditions. J. Plant Physiol. 2016, 201, 28-41. [CrossRef]

51. Bharti, N.; Barnawal, D.; Shukla, S.; Tewari, S.K.; Katiyar, R.S.; Kalra, A. Integrated application of Exiguobacterium oxidotolerans, Glomus fasciculatum, and vermicompost improves growth, yield and quality of Mentha arvensis in salt-stressed soils. Ind. Crops Prod. 2016, 83, 717-728. [CrossRef]

52. Hemashenpagam, N.; Selvaraj, T. Effect of arbuscular mycorrhizal (AM) fungus and plant growth promoting rhizomicroorganisms (PGPR). J. Environ. Biol. 2011, 32, 579-583.

53. Vogelsang, K.M.; Reynolds, H.L.; Bever, J.D. Mycorrhizal fungal identity and richness determine the diversity and productivity of a tallgrass prairie system. New Phytol. 2006, 172, 554-562. [CrossRef]

54. Piernik, A.; Hrynkiewicz, K.; Wojciechowska, A.; Szymanska, S.; Lis, M.; Muscolo, A. Effect of halotolerant endophytic bacteria isolated from salicornia europaea L. on the growth of fodder beet (Beta vulgaris L.) under salt stress. Arch. Agron. Soil Sci. 2017, 63, 1404-1418. [CrossRef]

55. Patel, D.; Jha, C.K.; Tank, N.; Saraf, M. Growth enhancement of chickpea in saline soils using plant growth-promoting rhizobacteria. J. Plant Growth Regul. 2012, 31, 53-62. [CrossRef] 
56. Niu, S.-Q.; Li, H.-R.; Paré, P.W.; Aziz, M.; Wang, S.-M.; Shi, H.; Li, J.; Han, Q.-Q.; Guo, S.-Q.; Li, J.; et al. Induced growth promotion and higher salt tolerance in the halophyte grass Puccinellia tenuiflora by beneficial rhizobacteria. Plant Soil 2016, 407, 217-230. [CrossRef]

57. Rewald, B.; Shelef, O.; Ephrath, J.E. Adaptive Plasticity of Salt-Stressed Root Systems. In Ecophysiology and Responses of Plants under Salt Stress; Springer: New York, NY, USA, 2013; pp. 169-201.

58. Poorter, H.; Niklas, K.J.; Reich, P.B.; Oleksyn, J.; Poot, P.; Mommer, L. Biomass allocation to leaves, stems and roots: Meta-analyses of interspecific variation and environmental control. New Phytol. 2012, 193, 30-50. [CrossRef] [PubMed]

59. Echeverria, M.; Scambato, A.A.; Sannazzaro, A.I.; Maiale, S.; Ruiz, O.A.; Menéndez, A.B. Phenotypic plasticity with respect to salt stress response by Lotus glaber: The role of its AM fungal and rhizobial symbionts. Mycorrhiza 2008, 18, 317-329. [CrossRef] [PubMed]

60. Brundrett, M. Mycorrhizas in natural Ecosystems. Adv. Ecol. Res. 1991, 21, 171-313.

61. Zou, Y.N.; Liang, Y.C.; Wu, Q.S. Mycorrhizal and non-mycorrhizal responses to salt stress in Trifoliate Orange: Plant growth, root architecture and soluble sugar accumulation. Int. J. Agric. Biol. 2013, 15, 565-569.

62. Wu, Q.S.; Zou, Y.N.; He, X.H. Contributions of arbuscular mycorrhizal fungi to growth, photosynthesis, root morphology and ionic balance of citrus seedlings under salt stress. Acta Physiol. Plant. 2010, 32, 297-304. [CrossRef]

63. Wang, Y.; Zhang, X.; Gao, Z.; Liu, W.; Wang, Q. Effect of salt on seedlings biomass of two varieties of Elaeagnus spp. China For. Sci. Technol. 2010, 24, 25-28.

64. Brundrett, M.C. Coevolution of roots and mycorrhizas of land plants. New Phytol. 2010, 154, $275-304$. [CrossRef]

65. Dodd, I.C.; Perez-Alfocea, F. Microbial amelioration of crop salinity stress. J. Exp. Bot. 2012, 63, 3415-3428. [CrossRef]

66. Hodge, A. The plastic plant: Root responses to heterogeneous supplies of nutrients. New Phytol. 2004, 162, 9-24. [CrossRef]

67. Bano, A.; Fatima, M. Salt tolerance in Zea mays L. following inoculation with Rhizobium and Pseudomonas. Biol. Fertil. Soils 2009, 45, 405-413. [CrossRef]

68. Evelin, H.; Giri, B.; Kapoor, R. Contribution of Glomus intraradices, inoculation to nutrient acquisition and mitigation of ionic imbalance in NaCl-stressed Trigonella foenum-graecum. Mycorrhiza 2012, 22, $204-217$. [CrossRef] [PubMed]

69. Murkute, A.A.; Sharma, S.; Singh, S.K. Studies on salt stress tolerance of citrus rootstock genotypes with arbuscular mycorrhizal fungi. Hortic. Sci. UZPI Czech Repub. 2006, 33, 70-76. [CrossRef]

70. Campanelli, A.; Ruta, C.; Mastro, G.; Morone-Fortunato, I. The role of arbuscular mycorrhizal fungi in alleviating salt stress in Medicago satival Var. Icon. Symbiosis 2013, 59, 65-76. [CrossRef]

71. Ciftci, V.; Turkmen, O.; Erdinc, C.; Sensoy, S. Effects of different arbuscular mycorrhizal fungi (AMF) species on some bean (Phaseolus vulgaris L.) cultivars grown in salty conditions. Afr. J. Agric. Res. 2010, 5, 3408-3416.

72. Stella, L.; Antonio, S.; Michele, P.; Teodoro, D.T.; Adriano, S. Abscisic acid root and leaf concentration in relation to biomass partitioning in salinized tomato plants. J. Plant Physiol. 2012, 169, 226-233.

73. Parida, A.K.; Das, A.B. Salt tolerance and salinity effects on plants: A review. Ecotoxicol. Environ. Saf. 2005, 60, 324-349. [CrossRef]

74. Al-Karaki, G.N.; Rusan, R.H.M. Response of two cultivars differing in salt tolerance to inoculation with mycorrhizal fungi under salt stress. Mycorrhiza 2001, 11, 43-47. [CrossRef]

75. Elhindi, K.M.; El-Din, A.S.; Elgorban, A.M. The impact of arbuscular mycorrhizal fungi in mitigating salt-induced adverse effects in sweet basil (Ocimum basilicum L.). Saudi J. Biol. Sci. 2017, 24, 170-179. [CrossRef]

76. Lin, J.; Wang, Y.; Sun, S.; Mu, C.; Yan, X. Effects of arbuscular mycorrhizal fungi on the growth, photosynthesis and photosynthetic pigments of Leymus chinensis seedlings under salt-alkali stress and nitrogen deposition. Sci. Total Environ. 2017, 576, 234-241. [CrossRef] [PubMed]

77. Zhu, X.Q.; Tang, M.; Zhang, H.Q. Arbuscular mycorrhizal fungi enhanced the growth, photosynthesis, and calorific value of black locust under salt stress. Photosynthetica 2017, 55, 378-385. [CrossRef]

78. Ahmad, P.; Azooz, M.M.; Prasad, M.N.V. Ecophysiology and Responses of Plants under Salt Stress; Springer: Berlin, Germany, 2013. 
79. De-Bashan, L.E.; Hernandez, J.P.; Bashan, Y. The potential contribution of plant growth-promoting bacteria to reduce environmental degradation-A comprehensive evaluation. Appl. Soil Ecol. 2012, 61, 171-189. [CrossRef]

80. Rietz, D.N.; Haynes, R.J. Effects of irrigation-induced salinity and sodicity on soil microbial activity. Soil Biol. Biochem. 2003, 35, 845-854. [CrossRef]

81. Ash, C. Fungi help trees hunt for food. Science 2016, 353, 661. [CrossRef]

(C) (1)

(C) 2020 by the authors. Licensee MDPI, Basel, Switzerland. This article is an open access article distributed under the terms and conditions of the Creative Commons Attribution (CC BY) license (http://creativecommons.org/licenses/by/4.0/). 